\title{
Incentivos para Internacionalização são Adequados? Percepção dos Pesquisadores em Administração da Informação
}

\section{Are Incentives for Internationalization Appropriate? Perception of Researchers in Information Systems} \\ Eduardo H. Diniz ${ }^{1}$ \\ (D) https://orcid.org/0000-0002-7950-9146 \\ Henrique Pontes Gonçalves de Oliveira ${ }^{1}$ \\ (iD) https://orcid.org/0000-0002-5927-7237 \\ José Eduardo Ricciardi Favaretto ${ }^{1}$ \\ (iD) https://orcid.org/0000-0002-0143-0809 \\ Débora Richter Brólio ${ }^{1}$ \\ (iD) https://orcid.org/0000-0003-0444-1068
}

Fundação Getulio Vargas, Escola de Administração de Empresas de São Paulo, São Paulo, SP, Brasil ${ }^{1}$

Artigo recebido em 05.09.2018. Última versão recebida em 15.05.2019. Aprovado em 15.05.2019. Editor-chefe: Prof. Wesley Mendes-Da-Silva.

\# de revisores convidados até a decisão

\begin{tabular}{|c|c|c|c|c|c|c|c|c|}
\hline & 1 & 2 & 3 & 4 & 5 & 6 & 7 & 8 \\
\hline $\mathbf{1}^{\mathbf{a}}$ rodada & $\stackrel{p}{2}$ & $\otimes$ & 2 & & & & & \\
\hline $2^{\mathrm{a}}$ rodada & 2 & & & & & & & \\
\hline $3^{a}$ rodada & 2 & & & & & & & \\
\hline $4^{a}$ rodada & 2 & & & & & & & \\
\hline $5^{\mathrm{a}}$ rodada & 2 & & & & & & & \\
\hline
\end{tabular}




\title{
Resumo
}

A internacionalização está se tornando cada vez mais importante para a academia brasileira e para a área de Administração em particular. Para entendermos quais práticas institucionais influenciam a inserção internacional de nossos pesquisadores, analisamos 172 questionários com dados de pesquisadores de 17 estados em Programas de Pós-Graduação nas mais importantes instituições do país. Apesar da coleta concentrada num segmento específico da área de Administração, pesquisadores em Administração de Informação (ADI), os resultados obtidos ilustram o comportamento de toda a área, pois este segmento está sujeito aos mesmos programas de incentivo que seus colegas de outras sub-áreas. Para esses pesquisadores, doutorado no exterior, completo ou sanduíche, é o principal elemento que explica a possibilidade de publicação internacional. O resultado do estudo apresentado neste artigo também aponta que que os pesquisadores não têm acesso aos mecanismos de incentivo considerados mais relevantes para atingir um maior nível de internacionalização. A partir da análise dos dados, é possível notar que esses respondentes entendem que os modelos de incentivos existentes em suas instituições precisam de ajustes para melhor incluir o país no sistema global de inovação.

Palavras-chave: internacionalização da pesquisa; administração de empresas; apoio institucional; inserção internacional; percepção dos pesquisadores.

\begin{abstract}
Internationalization is becoming increasingly important for the Brazilian academy and for the Administration area in particular. To understand which institutional practices influence the international insertion of our researchers, we analyzed 172 questionnaires with data from researchers from Graduate Programs in 17 states at the most important institutions of the country. Despite the data collection focused on a specific segment of the Administration area, researchers in Information Administration (ADI), the results obtained illustrate the behavior of the entire Administration field, since this segment is subject to the same incentive programs as its colleagues from other sub-areas. For these researchers, doctorate abroad, complete or sandwich, is the main element that explains the possibility of international publication. The result of the study presented in this article also points out that researchers do not have access to what they consider the most relevant incentive mechanisms to reach a higher level of internationalization. From the data analysis, it is possible to note that these respondents understand that the incentive models in their institutions need adjustments to better include the country in the global innovation system.
\end{abstract}

Keywords: internationalization of research; business administration; institutional support; international insertion; researchers' perception.

JEL Code: O3, M15, F42. 


\section{Introdução}

A internacionalização da academia brasileira é estimulada há anos por ações governamentais e ações das próprias instituições, públicas ou privadas, nas quais os pesquisadores estão afiliados. Também os Programas de Pós-Graduação (PPGs) da área de Administração reiteram que atividades de inserção internacional são prioritárias para o desenvolvimento nos programas (Coordenação de Aperfeiçoamento de Pessoal de Nível Superior [CAPES], 2016). Este aspecto ganha crescente interesse nas discussões da comunidade científica nos campos de estudos da área de Administração de Empresas do País e, dessa forma, torna-se importante investigar e compreender as ações para a inserção internacional das pesquisas geradas nos PPGs do Brasil, motivadas pela ação individual dos pesquisadores, apoiadas ou não pelas suas instituições de origem.

Este artigo propõe a investigação sobre as estratégias de internacionalização dos pesquisadores, a partir uma survey na qual foram avaliadas 172 respostas de pesquisadores atuantes na área de Administração da Informação (ADI). Desta pesquisa, é possível compreender como os pesquisadores deste campo avaliam a necessidade de internacionalização de suas pesquisas, como tem sido as suas estratégias de ação neste sentido e quais políticas institucionais mais contribuem com a globalização da pesquisa brasileira.

Embora usando dados de pesquisadores em atuação na sub-área de Administração de Informação, este artigo pretende ser de utilidade para toda a área de Administração de Empresas. Pesquisas anteriores propõe um modelo teórico composto de três dimensões - Formação, Disseminação e Colaboração - para o entendimento da internacionalização acadêmica (Diniz, Favaretto, Oliveira, \& Brólio, 2017; Heinzl, Winter, \& Bichler, 2015). Embora tenha grande utilidade para entender a internacionalização dos pesquisadores, este modelo de três dimensões não captura o papel das ações institucionais dos PPGs neste processo e portanto não distingue as motivações individuais do pesquisador daquelas que lhe são imputadas pelo ambiente institucional.

Nosso estudo contribui com a análise da dimensão relacionada ao ambiente institucional no qual o pesquisador está inserido e que influencia as suas ações individuais. A partir desta dimensão institucional, pode-se avaliar a efetividade das ações de internacionalização promovidas pelas instituições ao qual esses pesquisadores estão vinculados. Este artigo pretende ser de utilidade para gestores de instituições públicas e privadas, formadores de políticas públicas e agentes públicos (ex.: CAPES) ao apresentar a percepção dos pesquisadores sobre as políticas institucionais existentes e os elementos que eles avaliam como sendo mais efetivos para a internacionalização das pesquisas do campo.

Apesar do processo de internacionalização de nossa academia já ter sido tema de outros estudos (Bertero, Silveira, Cabral, Faria, \& Rossoni, 2013), não temos conhecimento de nenhum outro que tenha abordado diretamente os pesquisadores da área de Administração para identificar os mecanismos de incentivo institucionais para internacionalização existentes. Conhecer os incentivos institucionais existentes e sua influência na decisão dos pesquisadores é crucial para podermos avaliar e aperfeiçoar esses mecanismos e produzirmos resultados mais efetivos para internacionalizar a nossa pesquisa.

\section{Revisão de Literatura}

A temática da internacionalização do ensino e pesquisa é amplamente debatida na área de conhecimento da Educação por diversos aspectos. Entre eles estão comparação do desempenho acadêmico entre países (Bentley \& Kyvik, 2013; Kwiek, 2016), a mobilidade acadêmica de estudantes e professores, a publicação científica internacional como disseminação e transferência de conhecimento, a colaboração internacional em pesquisa (Knight, 2007; Rostan, Ceravolo, \& Metcalfe, 2014), além de discussões sobre a produtividade acadêmica (Shin \& Cummings, 2010). 
De acordo com Heinzl, Winter e Bichler (2015), há três formas primárias de determinada comunidade de pesquisa 'exportar' conhecimento: publicar a pesquisa em periódicos ou congressos internacionais, participar na condução de projetos internacionais de pesquisa, ou fazer a própria transferência física do acadêmico para o exterior. Pode-se entender a internacionalização das pesquisas brasileiras do campo de ADI a partir dessas três dimensões: identificação do país de formação dos pesquisadores, avaliação da disseminação internacional da sua produção científica e envolvimento dos pesquisadores da comunidade em redes internacionais de colaboração. O estudo de Diniz, Favaretto, Oliveira e Brólio (2017) aprofundou a investigação da internacionalização com base no modelo constituído por estas mesmas três dimensões de análise, mas considerou apenas a performance individual dos pesquisadores, sem levar em conta a influência do ambiente institucional no qual estes pesquisadores estão inseridos.

A disponibilidade de recursos financeiros para a pesquisa, a existência de mecanismos de recompensa ou premiação aos pesquisadores, a cultura departamental e condições de trabalho, a distribuição de tempo dedicado entre ensino e pesquisa, o apoio de pessoal administrativo, as normas disciplinares da instituição, a orientação-foco da instituição, a missão institucional, a formação de redes de alianças estratégicas, visiting lectures e scholars são variáveis institucionais identificadas na literatura que podem influenciar na produtividade dos pesquisadores e, por consequência, na internacionalização de suas pesquisas (Bentley \& Kyvik, 2012, 2013; Knight, 2007; Kwiek, 2016; Rostan et al., 2014; Shin \& Cummings, 2010). As recomendações da área de Administração na CAPES (2016) também sugerem aos PPGs ações institucionais que estimulem a inserção internacional de seus pesquisadores, como por exemplo: o trânsito de pesquisadores para grupos de pesquisa fora do Brasil, o recrutamento de pesquisadores estrangeiros para compor o corpo docente do PPG, além de acordos para dupla titulação com instituições internacionais.

Estudo de Kwiek (2016) avaliou a produtividade da pesquisa de acadêmicos europeus de 11 países, baseado no modelo de utilização de variáveis individuais e institucionais, e identificou que a importância dessas variáveis era diferente de um país para outro. Conforme esse estudo, fatores institucionais impactavam muito pouco no incremento da produtividade da pesquisa quando comparado aos fatores individuais - com exceção para o Reino Unido e Suíça. Por outro lado, Shin e Cummings (2010) identificaram que o apoio de pessoal administrativo e a orientação-foco da instituição tiveram efeito significante na disseminação internacional das pesquisas.

Os autores Bentley e Kyvik $(2012,2013)$ compararam a distribuição do tempo dedicado dos pesquisadores de 13 países nas atividades de ensino/pesquisa e concluíram que tais diferenças eram influenciadas por normas disciplinares ou particularidades da instituição onde o pesquisador estava alocado. Dentre os países considerados, este estudo aponta que brasileiros e malaios, diferentemente de colegas da Finlândia, a Noruega, o Canadá e Hong Kong, dedicam menor número de horas para a pesquisa, mesmo quando estão em períodos liberados das atividades de docência.

De acordo com Knight (2007), a formação de redes e alianças estratégicas podem ser vistas como maneiras institucionais para promover a internacionalização das pesquisas favorecendo vários propósitos, tais como: mobilidade acadêmica, iniciativas de pesquisa e educação colaborativas, desenvolvimento de programas e currículos conjunto para alcançar objetivos acadêmicos, científicos e culturais, além de também serem vistos como meios de aproximação e cooperação bilateral para obter vantagem competitiva.

A despeito da identificação de mecanismos institucionais e de comportamentos individuais dos pesquisadores, a literatura existente carece de uma análise que explique o perfil de internacionalização dos pesquisadores brasileiros na área de Administração a partir das ações institucionais das organizações das quais os pesquisadores fazem parte. Assim, além das dimensões formação, disseminação e colaboração detalhadas por Diniz et. al (2017) para entender o comportamento individual dos pesquisadores, acreditamos ser importante considerar uma dimensão institucional. Embora este artigo não tenha a pretensão de validar uma nova dimensão ao modelo identificado na literatura, acreditamos que a identificação conceitual desta nova dimensão possa estimular estudos futuros que possam validála adequadamente. 
Apenas com o intuito de apontar algumas variáveis relacionadas a esta dimensão institucional, identificamos via literatura (Bentley \& Kyvik, 2012, 2013; Knight, 2007; Kwiek, 2016; Rostan et al., 2014; Shin \& Cummings, 2010), uma lista de ações institucionais de apoio à internacionalização. Entre elas estão: diretrizes para disponibilização de recursos para a pesquisa, mecanismos de recompensa ou premiação aos pesquisadores, cultura departamental e condições de trabalho, alocação de tempo dedicado entre ensino e pesquisa, apoio de pessoal administrativo (staff), normas disciplinares da instituição, apoio à formação de redes de alianças estratégicas, e convites para visiting scholars.

Baseado nessas ações institucionais, estruturamos nosso modelo de coleta e análise de dados que permitiu avaliar o peso relativo de cada uma delas nas ações de internacionalização dos pesquisadores.

\section{Metodologia e Coleta de Dados}

Apesar de propormos neste artigo uma discussão sobre a internacionalização em toda a área de Administração, a pesquisa apresentada neste estudo foi operacionalizada com dados do campo de Administração de Informação (ADI). Justificamos esta abordagem de pesquisa focada numa sub-área do campo de Administração por três razões principais. A primeira é pelo fato da área de Administração ser muito diversificada e portanto representa-la como um todo numa pesquisa única seria operacionalmente muito complexo em termos da identificação universo dos pesquisadores envolvidos, incluindo suas intersecções com áreas adjacentes, e a forma como cada sub-área elege seus congressos e periódicos prioritários. A segunda razão está relacionada ao fato da área de ADI possuir temáticas alinhadas com a internacionalização (Walsham, Robey, \& Sahay, 2007), enquanto outras sub-áreas, por exemplo a área de recursos humanos, possuírem relação mais forte com elementos da cultura local (Wood, Tonelli, \& Cooke, 2011). Por último, como o foco deste artigo são os mecanismos de incentivo existentes nas instituições de ensino e pesquisa, é óbvio que esses mecanismos valem igualmente para pesquisadores de todas as sub-áreas, pois não se tem notícia de alguma instituição que tenha incentivos desenhados por sub-área de conhecimento. Assim, as possíveis influências dos incentivos para internacionalização existentes em uma instituição devem impactar igualmente tanto os pesquisadores de ADI quanto os de Marketing, por exemplo.

Quatro fontes de dados foram acessadas para identificação dos potenciais respondentes para esta pesquisa: (a) Instituições de Ensino Superior (IES) com PPGs e Linha de Pesquisa em ADI com nota igual ou superior a 3, atribuída pela CAPES; (b) páginas da Associação Nacional de Pós-graduação e Pesquisa em Administração (ANPAD) que traziam os nomes dos coordenadores ou líderes de trilha da área temática de ADI nos congressos do EnANPAD e EnADI; (c) artigos completos publicados nestes mesmos congressos no período de 2010 a 2015; (d) artigos de autores brasileiros com publicação nos periódicos acadêmicos Journal of Information Systems and Technology Management (JISTEM) e Revista Eletrônica de Sistemas de Informação (RESI) no período de 2010 a 2015 . A partir da análise destas bases, foi possível construir uma lista com 554 nomes de pesquisadores com atividade em ADI e localizados 533 e-mails individuais corretos para contato.

Para a realização da coleta de dados com esses pesquisadores, foi construída uma websurvey, realizada de setembro a outubro de 2016, por meio de um link encaminhado, por e-mail, para um universo de 533 pesquisadores da área de ADI. Após esta convocação geral a todos os pesquisadores desta sub-área.

O questionário desta websurvey foi dividido em três grupos de questões: (a) percepção sobre a efetividade de incentivos institucionais à internacionalização; (b) incentivos para internacionalização existentes nas instituições dos respondentes; (c) perfil de internacionalização dos respondentes com base nas dimensões formação, disseminação e colaboração. 
Com base nos três grupos de questões, elaboramos duas hipóteses para avaliar a efetividade dos incentivos institucionais que os respondentes consideram mais importantes para internacionalização e que estão sendo aplicados nas instituições às quais estão vinculados.

Nossa primeira hipótese, H1, afirma que os pesquisadores não têm os incentivos que eles consideram mais importantes para a internacionalização da sua pesquisa. Esta hipótese foi proposta com base no reconhecimento geral do nível de internacionalização relativamente baixo de nossa comunidade acadêmica.

Nossa segunda hipótese, H2, afirma que aqueles pesquisadores com acesso aos incentivos considerados mais importantes por eles próprios, conseguem publicações em periódicos mais relevantes. Para identificação dos periódicos relevantes consideramos no questionário apenas periódicos classificados na lista Qualis como A1 ou A2 internacional, ou ainda com fator de impacto para entrar nesta lista. Esta hipótese foi proposta com base na expectativa da efetividade dos incentivos considerados mais importantes, de acordo com a opinião dos próprios pesquisadores participantes da pesquisa.

Com bases nesses dados, elaboramos também análises de regressão para identificar dentre os mecanismos de incentivos aqueles que, na opinião dos respondentes, melhor contribuem para a internacionalização. Realizamos também análise de clusterização para identificar grupos de perfis entre os respondentes, mas o resultado obtido não permitiu nenhuma análise conclusiva, motivo pelo qual excluímos do artigo a discussão sobre a clusterização dos respondentes.

\section{Amostra considerada}

O questionário foi elaborado na primeira quinzena de 2016, considerando sua montagem na página do websurvey, pelo grupo de pesquisa, e submetido a 4 pesquisadores para a realização do préteste. Após o pré-teste, o questionário foi ajustado e a pesquisa foi disponibilizada para coleta de dados em meados de setembro de 2016, quando foi encaminhado o link da websurvey aos potenciais respondentes, via e-mail. Os dados deste questionário foram coletados entre setembro e novembro de 2016, com o convite reforço feito após o período do EnANPAD 2016. Durante o EnANPAD daquele ano, foi feita uma força tarefa dos pesquisadores para divulgar a pesquisa e questionários também foram coletados durante o evento, o que pode ter contribuído para algum viés da amostra para os pesquisadores participantes daquele evento. A coleta de dados foi finalizada no início de novembro de 2016.

Optamos por um questionário em que a identificação dos respondentes não era obrigatória, com o objetivo de encorajar a participação e fidedignidade das respostas (Hewson, Laurent, \& Vogel, 1996; Schmidt, 1997). Na parte de identificação do respondente, solicitamos apenas que fosse indicada a principal instituição acadêmica de atuação, vínculo com instituição não acadêmica, caso houvesse, gênero e perfil de atuação.

Foram obtidas 177 respostas, das quais 172 foram consideradas válidas - 32,3\% do universo de 533 convites enviados a potenciais respondentes. Dessa forma, foram analisadas as 172 respostas válidas de pesquisadores com doutorado completo. A Tabela 1 apresenta a lista das instituições nas quais os respondentes estão vinculados. 
Tabela 1

Instituições de Ensino Superior dos Respondentes

\begin{tabular}{lcc}
\hline Instituição de Ensino Superior (IES) & Pesquisadores (n=172) & \% \\
\hline USP - Universidade de São Paulo & 16 & $9,3 \%$ \\
\hline PUC/PR - Pontifícia Universidade Católica do Paraná & 7 & $4,1 \%$ \\
\hline PUC/RS - Pontifícia Universidade Católica do Rio Grande do Sul & 7 & $4,1 \%$ \\
\hline UFRGS - Universidade Federal do Rio Grande do Sul & 7 & $4,1 \%$ \\
\hline FGV - Fundação Getulio Vargas & 6 & $3,5 \%$ \\
\hline UNINOVE - Universidade Nove de Julho & 6 & $3,5 \%$ \\
\hline UNIRIO - Universidade Federal do Estado do Rio de Janeiro & 6 & $3,5 \%$ \\
\hline UFPR - Universidade Federal do Paraná & 5 & $2,9 \%$ \\
\hline UFSM - Universidade de Santa Maria & 5 & $2,9 \%$ \\
\hline UNISINOS - Universidade da Vale do Rio dos Sinos & 5 & $2,9 \%$ \\
\hline UnB - Universidade de Brasília & 5 & $2,9 \%$ \\
\hline UFF - Universidade Federal Fluminense & 4 & $2,3 \%$ \\
\hline PUC/MG - Pontifícia Universidade Católica de Minas Gerais & 4 & $2,3 \%$ \\
\hline UFRN - Universidade Federal do Rio Grande do Norte & 3 & $1,7 \%$ \\
\hline Outras Instituições & 86 & $50 \%$ \\
\hline
\end{tabular}

Nota. As Instituições de Ensino Superior (IES) e o número de pesquisadores (respondentes) que possuem vinculação acadêmica nessas instituições $(\mathrm{n}=172)$. Os nomes de IES com único pesquisador estão acumulados em Outras Instituições.

Como podemos observar na Tabela 2, ao compararmos o perfil dos 172 pesquisadores respondentes observou-se que estes possuem um perfil de internacionalização superior àquele do universo de 533 pesquisadores para os quais foram encaminhados o convite inicial para participação na pesquisa. Este maior nível de internacionalização da amostra em comparação com o universo parece plausível, pois o tema da internacionalização tende a atrair mais o interesse daqueles que já fazem algum movimento neste sentido.

No entanto, ao separarmos do universo total de 533 pesquisadores aqueles que possuem alguma formação internacional via doutorado no exterior ou publicação internacional, encontramos um subgrupo com 343 pesquisadores ao qual classificamos como pesquisadores internacionalizados. Observamos que o nível de internacionalização da amostra de 172 pesquisadores respondentes é mais próximo do sub-grupo mais internacionalizado do que do universo total, o que também seria de se esperar. Outra característica desta amostra é que ela apresenta uma predominância de pesquisadores do gênero masculino (69\%), conforme observado na Tabela 2. 
Tabela 2

Perfil dos Respondentes

\begin{tabular}{|c|c|c|c|c|c|c|c|c|}
\hline \multirow{2}{*}{$\begin{array}{l}\text { Dimensão } \\
\text { Publicação }\end{array}$} & \multicolumn{2}{|c|}{ Características } & \multicolumn{2}{|c|}{$\begin{array}{c}\text { Pesquisadores } \\
\text { convidados } \\
\mathbf{5 3 3}\end{array}$} & \multicolumn{2}{|c|}{$\begin{array}{c}\text { Pesquisadores } \\
\text { internacionalizados } \\
\mathbf{3 4 3}\end{array}$} & \multicolumn{2}{|c|}{$\begin{array}{l}\text { Pesquisadores } \\
\text { respondentes } \\
\text { avaliados } \\
\mathbf{1 7 2}\end{array}$} \\
\hline & Periódico & Sim & 192 & $36 \%$ & 192 & $56 \%$ & 84 & $49 \%$ \\
\hline \multirow[t]{3}{*}{ Internacional } & & Não & 341 & $64 \%$ & 151 & $44 \%$ & 88 & $51 \%$ \\
\hline & Congresso & Sim & 194 & $36 \%$ & 194 & $57 \%$ & 130 & $76 \%$ \\
\hline & & Não & 339 & $64 \%$ & 149 & $43 \%$ & 42 & $24 \%$ \\
\hline \multirow{2}{*}{$\begin{array}{l}\text { Formação } \\
\text { Exterior }\end{array}$} & Doutorado & Sim & 70 & $13 \%$ & 70 & $20 \%$ & 19 & $11 \%$ \\
\hline & & Não & 463 & $87 \%$ & 273 & $80 \%$ & 153 & $89 \%$ \\
\hline \multirow[t]{2}{*}{ Gênero } & & Masc. & 370 & $67 \%$ & 247 & $72 \%$ & 118 & $69 \%$ \\
\hline & & Fem. & 183 & $33 \%$ & 96 & $28 \%$ & 54 & $31 \%$ \\
\hline
\end{tabular}

Nota. Comparativo entre os 533 pesquisadores convidados para a pesquisa, os 343 pesquisadores mais internacionalizados deste universo (com formação ou alguma publicação internacional) e os 172 respondentes da pesquisa. Fonte: Elaborado pelos autores.

Como mostra a Tabela 3, foi possível traçar um perfil das instituições dos pesquisadores, predominando a atuação em instituições públicas (65,7\%), sendo 46,5\% em instituições federais, $12.8 \%$ em estaduais e $6,4 \%$ em municipais. Também se observa uma boa quantidade de pesquisadores atuando em instituições com avaliação Capes 5, 6 e $7(49,4 \%)$ e $4(30,2 \%)$, o que é de se esperar se considerarmos o tema da pesquisa, a exigência de doutorado para participar e também a ênfase na divulgação feita em torno dos participantes do EnANPAD. Alguns dos pesquisadores identificados no universo são pertencentes a instituições não acadêmicas e a instituições acadêmicas que não têm programas reconhecidos pela Capes e foram ambos os tipos classificados na Tabela 3 como não reconhecidos pela Capes. Neste grupo de instituições não reconhecidas, encontram-se tanto instituições que não possuem programas de doutorado, sejam públicas ou privadas, quanto instituições que foram avaliadas pela Capes com notas inferiores a 3. Com relação a distribuição geográfica, as regiões Sudeste $(44,2 \%)$ e Sul $(36,0 \%)$, concentram a maior parte dos pesquisadores.

Tabela 3

Perfil das Instituições dos Respondentes

\begin{tabular}{|c|c|c|c|c|c|c|c|}
\hline \multirow{2}{*}{$\begin{array}{l}\text { Dimensão } \\
\text { Tipo }\end{array}$} & \multirow{2}{*}{$\begin{array}{l}\text { Características } \\
\text { Pública Federal }\end{array}$} & \multicolumn{2}{|c|}{$\begin{array}{l}\text { Pesquisadores } \\
\text { convidados } \\
533\end{array}$} & \multicolumn{2}{|c|}{$\begin{array}{c}\text { Pesquisadores } \\
\text { internacionalizados } \\
\mathbf{3 4 3}\end{array}$} & \multicolumn{2}{|c|}{$\begin{array}{l}\text { Pesquisadores } \\
\text { respondentes } \\
\text { avaliados } \\
172\end{array}$} \\
\hline & & 232 & $43,5 \%$ & 157 & $45,8 \%$ & 80 & $46,5 \%$ \\
\hline & Privada & 178 & $33,4 \%$ & 108 & $31,5 \%$ & 58 & $33,7 \%$ \\
\hline & Pública Estadual & 86 & $16,1 \%$ & 58 & $16,9 \%$ & 22 & $12,8 \%$ \\
\hline & Pública Municipal & 27 & $5,1 \%$ & 13 & $3,8 \%$ & 11 & $6,4 \%$ \\
\hline & Exterior & 3 & $0,6 \%$ & 1 & $0,3 \%$ & 1 & $0,6 \%$ \\
\hline & Não Informado & 7 & $1,3 \%$ & 6 & $0,3 \%$ & - & - \\
\hline
\end{tabular}


Tabela 3 (continuação)

\begin{tabular}{|c|c|c|c|c|c|c|c|}
\hline \multirow{5}{*}{$\begin{array}{l}\text { Dimensão } \\
\begin{array}{l}\text { Avaliação } \\
\text { Capes }\end{array}\end{array}$} & \multirow{2}{*}{$\begin{array}{l}\text { Características } \\
\text { Capes } 5,6 \text { e } 7\end{array}$} & \multicolumn{2}{|c|}{$\begin{array}{c}\text { Pesquisadores } \\
\text { convidados } \\
533\end{array}$} & \multicolumn{2}{|c|}{$\begin{array}{c}\text { Pesquisadores } \\
\text { internacionalizados } \\
\mathbf{3 4 3}\end{array}$} & \multicolumn{2}{|c|}{$\begin{array}{c}\text { Pesquisadores } \\
\text { respondentes } \\
\text { avaliados } \\
172 \\
\end{array}$} \\
\hline & & 238 & $44,7 \%$ & 160 & $46,6 \%$ & 85 & $49,4 \%$ \\
\hline & Capes 4 & 157 & $29,5 \%$ & 104 & $30,3 \%$ & 52 & $30,2 \%$ \\
\hline & Capes 3 & 92 & $17,3 \%$ & 52 & $15,2 \%$ & 33 & $19,2 \%$ \\
\hline & Não reconhecidas & 46 & $8,6 \%$ & 27 & $7,9 \%$ & 2 & $1,2 \%$ \\
\hline \multirow[t]{7}{*}{ Região } & Sudeste & 272 & $51,0 \%$ & 175 & $51,0 \%$ & 76 & $44,2 \%$ \\
\hline & Sul & 165 & $31,0 \%$ & 102 & $29,7 \%$ & 62 & $36,0 \%$ \\
\hline & Nordeste & 48 & $9,0 \%$ & 35 & $10,2 \%$ & 21 & $12,2 \%$ \\
\hline & Centro-oeste & 31 & $5,8 \%$ & 23 & $6,7 \%$ & 7 & $4,1 \%$ \\
\hline & Norte & 8 & $1,5 \%$ & 1 & $0,3 \%$ & 5 & $2,9 \%$ \\
\hline & Exterior & 3 & $0,6 \%$ & 1 & $0,3 \%$ & 1 & $0,6 \%$ \\
\hline & Não informado & 7 & $1,3 \%$ & 6 & $1,7 \%$ & - & - \\
\hline
\end{tabular}

Nota. Comparativo das características observadas entre as instituições dos 533 pesquisadores convidados para a pesquisa, os 343 pesquisadores com perfil internacionalizado e os 172 respondentes avaliados. Fonte: Elaborado pelos autores com os dados da pesquisa.

Tomamos a decisão de não segmentar a amostra (pesquisadores de instituições públicas versus pesquisadores de instituições privadas, por exemplo) nas análises feitas neste estudo, mesmo reconhecendo a importância das análises com este tipo de segmentação poderiam trazer. Avaliamos que quebrar a amostra em segmentos menores poderia enfraquecer a análise de regressão proposta para entender a efetividade dos incentivos institucionais de forma geral. Assim, como vai ser apresentado na próxima seção, o foco da análise foi feito exclusivamente sobre a amostra total de 172 respondentes e pode trazer uma série de observações relevantes para compreender a influência do ambiente institucional do pesquisador nas suas ações individuais para internacionalizar sua pesquisa.

\section{Resultados}

Os resultados da análise dos dados coletados dos 172 pesquisadores, foram organizados em três partes. Na primeira parte analisamos com base apenas em estatística descritiva o perfil de internacionalização dos respondentes, com base nas dimensões formação, disseminação e colaboração discutidas anteriormente neste artigo. Na segunda parte apresentamos a percepção de importância que os pesquisadores têm sobre diversos tipos de incentivos existentes e quais incentivos estão efetivamente presentes em suas instituições. Na terceira parte dos resultados, utilizamos técnicas de regressão para testar as hipóteses $\mathrm{H} 1$ e $\mathrm{H} 2$ propostas anteriormente e também para identificar as variáveis que possuem maior impacto no processo de internacionalização, segundo a opinião dos respondentes.

\section{O perfil de internacionalização dos respondentes}

As perguntas sobre o perfil de internacionalização dos pesquisadores participantes do estudo, considerando as dimensões formação, disseminação e colaboração, conforme identificadas na teoria e detalhada na seção de revisão de literatura deste artigo. A seguir a descrição deste perfil, seguindo as dimensões consideradas. 


\section{Dimensão formação internacional}

$\mathrm{Na}$ dimensão Formação internacional, observamos que entre os respondentes $11 \%$ fizeram doutorado completo no exterior, $26 \%$ tiveram bolsa sanduíche, ou seja, fizeram parte do seu doutorado no exterior e também $26 \%$ participaram de algum tipo de atividade no exterior após terem concluído seu doutorado. Nota-se por esses números que a experiência internacional do conjunto dos respondentes não é muito expressiva, talvez fruto de muitos terem se graduado num período em que a ênfase na internacionalização não era prioridade.

Entretanto, como a pressão por internacionalização é crescente, além da experiência internacional do próprio pesquisador, o item formação capturou também o estímulo dado aos orientandos para participarem de programas de doutorado sanduíche. A Tabela 4 mostra o envolvimento em programas sanduíche no perfil da orientação dos respondentes nos anos de 2015 e 2016, e a previsão para 2017, a partir da expectativa que os respondentes tinham no segundo semestre de 2016.

Dos resultados obtidos, percebe-se que $42 \%$ dos respondentes tiveram orientandos com experiência internacional em 2015, um número que indica um índice de internacionalização superior ao do próprio grupo de pesquisadores respondentes. Isso indica que nossos pesquisadores, em boa medida, valorizam o desenvolvimento de conexões no exterior, ainda que por meio de seus alunos. Esta resposta também está em sintonia com a alta importância (acima de 80\%) que os pesquisadores dão para o envio de alunos em programas sanduíche, expresso nas Figuras 1 e 2 apresentadas anteriormente. O número cai dramaticamente em 2016 (12\%), muito provavelmente como reflexo da crise econômica e do corte de bolsas. Os números de 2017 eram mais otimistas (53\%), provavelmente pela expectativa de retomada da melhora na economia associada com o crescimento da percepção da relevância de se estabelecer laços internacionais. Entretanto, com a persistência da crise, nada indica que este otimismo tenha tido oportunidade de se realizar.

Tabela 4

\section{Respondentes com Orientandos em Doutorado Sanduíche}

\begin{tabular}{lccc}
\hline $\begin{array}{l}\text { Quantidade de Doutorandos } \\
\text { com bolsa sanduíche }\end{array}$ & $\mathbf{2 0 1 5}$ & $\mathbf{2 0 1 6}$ & $\begin{array}{c}\text { (previsão) } \\
\mathbf{2 0 1 7}\end{array}$ \\
\hline Mais que 5 alunos & 8 & - & - \\
\hline Entre 3 e 5 alunos & 14 & - & - \\
\hline Menos que 3 alunos & 50 & - & - \\
\hline Mais que 2 alunos & - & 5 & 15 \\
\hline 2 alunos & - & 0 & 37 \\
\hline 1 aluno & - & 15 & 50 \\
\hline Nenhum & 96 & 148 & 66 \\
\hline Não respondeu & 04 & 04 & 04 \\
\hline
\end{tabular}

Nota. Quantidade de pesquisadores (n=172) com orientação de alunos que participaram (de 2015 a 2016) ou tinham previsão de participação (2017) em programa Doutorado Sanduiche. Fonte: Elaborado pelos autores.

Nos resultados obtidos, percebe-se que $42 \%$ dos respondentes tiveram orientandos com experiência internacional em 2015, um número que indica um índice de internacionalização superior ao do próprio grupo de pesquisadores respondentes. Isso indica que nossos pesquisadores captaram a importância de desenvolver laços no exterior, ainda que por meio de seus alunos. Esta resposta também está em sintonia com a alta importância (acima de 80\%) que os pesquisadores dão para o envio de alunos em programas sanduíche, expresso nas Figuras 1 e 2. O número cai dramaticamente em 2016 (12\%), muito provavelmente como reflexo da crise econômica e do corte de bolsas. Os números de 2017 eram mais otimistas (53\%), provavelmente pela expectativa de retomada da melhora na economia associada com o crescimento da percepção da relevância de se estabelecer laços internacionais. Entretanto, com a persistência da crise, nada indica que este otimismo tenha tido oportunidade de se realizar. 


\section{Dimensão disseminação internacional da pesquisa}

A Disseminação internacional da pesquisa foi identificada, em primeiro lugar, pelas informações sobre as publicações efetuadas em periódicos e congressos internacionais. Para os periódicos, foram considerados o número de artigos publicados pelo grupo de respondentes entre 2010 a 2016 (141 artigos), aqueles que estavam ainda em avaliação no ano de 2016 (79 artigos) e os que pretendiam submeter em 2017 (207 artigos). A análise destes números indica que este grupo de pesquisadores tem preocupação crescente com a publicação internacional como instrumento para construção de uma visibilidade internacional, dado que o número de submissões e publicações em periódicos de mais prestígio internacional está subindo.

Um outro aspecto sobre o perfil de publicação destes respondentes é o tipo de periódico internacional ao qual submeteram seus artigos, apresentado na Tabela 5. Embora nos artigos publicados haja predomínio de periódicos internacionais de perfil A2 ou menos relevantes, há também menção a periódicos de ponta de sua área, como MIS Quarterly, Journal of Management Information Systems e Informations Systems Research. O mesmo vale para os artigos que ainda estavam em avaliação e a expectativa de submissão. Neste último caso, o otimismo dos respondentes também se mostra presente, pois a quantidade de periódicos de ponta tem participação mais expressiva ainda, indicando que este grupo de pesquisadores sinaliza estar procurando se inserir na comunidade internacional nos canais de maior expressão possível, aumentando sua relevância na comunidade a que pertencem.

Tabela 5

Periódicos Internacionais em que os Respondentes Publicaram ou Pretendem Publicar

\begin{tabular}{|c|c|c|c|c|}
\hline Nome do Periódico Internacional /Classificação & $\begin{array}{c}\text { Qualis } \\
\text { (JCR 2018) }\end{array}$ & $\begin{array}{c}\text { Publicado } \\
2010 \text { a } 2016\end{array}$ & $\begin{array}{c}\text { Em avaliação } \\
(2016)\end{array}$ & $\begin{array}{c}\text { Pretende } \\
\text { submeter em } \\
2017 \\
\end{array}$ \\
\hline Academy of Management Journal & A1 $(6,700)$ & - & 2 & 5 \\
\hline Academy of Management Review & $\mathrm{ND}(8,855)$ & - & 1 & 3 \\
\hline Behavior \& Information Technology & A2 (ND) & 1 & - & 13 \\
\hline Computers in Human Behavior & $\mathrm{A} 2(3,536)$ & 4 & 1 & - \\
\hline Decision Support Systems & A1 $(3,565)$ & 3 & 4 & 13 \\
\hline European Journal of Information Systems & ND $(3,197)$ & - & 2 & 12 \\
\hline Information \& Management & A1 $(3,890)$ & 1 & 2 & 14 \\
\hline Information Systems Research & A1 $(2,301)$ & - & - & 6 \\
\hline Information Systems Frontiers & A1 $(3,232)$ & 2 & - & - \\
\hline Information Systems Journal & A1 $(4,267)$ & 2 & 6 & 16 \\
\hline Information Systems Management & A1 $(1,255)$ & 4 & 5 & 12 \\
\hline Journal of Global Information Management & A1 $(0,613)$ & 2 & - & - \\
\hline Journal of Information Technology & $\mathrm{A} 1(4,535)$ & 3 & 5 & 9 \\
\hline Journal of Management Information Systems & $\mathrm{ND}(2,744)$ & - & 1 & 10 \\
\hline Journal of Strategic Information Systems & A1 $(4,313)$ & 2 & - & 10 \\
\hline MIS Quarterly & A1 $(5,430)$ & 1 & 2 & 5 \\
\hline Organization Studies & A1 $(3,133)$ & 1 & 4 & 7 \\
\hline Production and Operations Management & A1 $(1,722)$ & - & 2 & 8 \\
\hline Outros & A2 & 101 & 40 & 64 \\
\hline Total & & 128 & 77 & 207 \\
\hline
\end{tabular}

Nota. Quantidades de artigos publicados (2010-2016) ou em avaliação (2016), e com submissão pretendida para 2017 em periódicos internacionais. Fonte: Elaborado pelos autores. 
Ainda na dimensão Disseminação, é possível avaliar com os dados da Tabela 6 o perfil dos respondentes com relação a participação em congressos internacionais. Entre 2010 e 2016 este grupo de pesquisadores apresentou 372 artigos e pretendiam submeter outros 346 artigos em congressos de 2017, o que significa um plano de crescimento significativo denotando que esses pesquisadores têm crescido a sua produção acadêmica e tem interesse cada vez maior em posiciona-la internacionalmente. Porém devemos levar em consideração o cenário econômico, nada otimista, dos anos que sucedem aos resultados desta pesquisa, considerando, principalmente a intenção dos pesquisadores. A menção a congressos importantes como AMCIS, ECIS e AoM, demonstra a busca por espaços de divulgação mais relevantes.

Tabela 6

Congressos Internacionais nos Quais os Respondentes Participaram ou Pretendem Participar

\begin{tabular}{lcc}
\hline Nome do Congresso Internacional & $\begin{array}{c}\text { Participação entre } \\
\text { 2010 e 2016 }\end{array}$ & $\begin{array}{c}\text { Intenção de } \\
\text { Submissão em 2017 }\end{array}$ \\
\hline ALTEC - Congresso Latino-Iberoamericano de Gestão de Tecnologia & 33 & 31 \\
\hline AMCIS - Americas Conference on Information Systems & 36 & 35 \\
\hline AoM - Academy of Management Annual Meeting & 14 & 20 \\
\hline BALAS - Business Association of Latin American Studies & 22 & 18 \\
\hline CLADEA - Consejo Latinoamericano de Escuelas de Administración & 28 & 22 \\
\hline Conf-IRM - International Conference on Information Resources & 28 & 24 \\
\hline Management & 13 & 25 \\
\hline ECIS - European Conference on Information Systems & 185 & 171 \\
\hline Total & 372 & 346 \\
\hline
\end{tabular}

Nota. Quantidade de Congressos internacionais com publicações dos respondentes no período de 2010 a 2016 e intenção de submissão no ano de 2017. Fonte: Elaborado pelos autores.

\section{Dimensão colaboração internacional}

Na dimensão Colaboração, os respondentes foram indagados a respeito de seu vínculo como membro de associações científicas internacionais, sua participação em comitês científicos internacionais, e sua participação em pesquisas internacionais.

Sobre participação em associações, parece claro que a comunidade de pesquisa investigada tem pouco interesse em se vincular a estas comunidades científicas de forma perene, tendendo a valorizar o pagamento da contribuição de associado apenas quando da participação em eventos organizados por essas associações. Para exemplificar este raciocínio e dado que o estudo focou o caso da sub-área de ADI, investigou-se com mais profundidade a participação junto à Association for Information Systems (AIS, n.d.). Conforme a intenção de vínculo dos pesquisadores a esta associação científica, 54 pesquisadores (31\%) afirmaram que são ou já foram associados; 24 pesquisadores (14\%) tem intenção em se associar no ano de 2017 e 55\% relatou que nunca foi associado e não teria intenção de se associar nos próximos meses. Outras associações importantes, como Academy of Management e IEEE (Institute of Electrical and Electronics Engineers) foram também mencionadas na pesquisa, mas sempre com números muito baixos de adesão.

A participação em comitês científicos internacionais foi classificada de acordo com a atuação do pesquisador em periódicos e congressos do campo, em que foi constatado: 1 participante como KeyNote Speaker, 23 participantes como Editores Associados (periódicos), 24 participantes como Chair ou Program Chair (congresso), 30 participantes como líderes de trilhas ou Track Chair (congresso), 82 participantes como Ad Hoc em congresso e 90 participantes como Ad Hoc em periódico. Sobre o perfil da participação em comitês científicos, percebe-se que cerca de metade dos respondentes ainda 
participam apenas nos comitês Ad Hoc, denotando ainda um envolvimento menos comprometido com a comunidade científica organizada em torno dos periódicos e congressos internacionais. Menos de $20 \%$ dos pesquisadores afirmaram ter participação mais significativa como editores associados e lideranças de tracks de periódicos e congressos internacionais.

A participação dos respondentes em projetos de colaboração internacional foi relatada considerando-se dois momentos da investigação. O primeiro, até o ano de 2016 (passado), onde 47\% dos pesquisadores confirmaram ter participado ou ainda participar de projeto com colaboração internacional, destacando como os principais países parceiros - com mais de 5 projetos - os EUA (14 projetos), França (14), Portugal (13), Espanha (12), Canadá (11), e Reino Unido (11). E o segundo momento, ano de 2017 (atual/futuro), onde 35\% confirmou que pretendem participar de algum projeto internacional de pesquisa, demonstrando articulação concentrada em parceiros de alguns países em particular: Portugal (16), Reino Unido (9), EUA (9), França (8) e Alemanha (5), estavam entre os mais citados. A análise desses dados indica que os pesquisadores que participaram deste estudo têm um nível de envolvimento razoável em projetos de pesquisa internacional. De qualquer forma, é um bom indicativo saber que nossa comunidade elegeu parcerias prioritárias com pesquisadores de países com forte tradição de pesquisa. Entretanto, com a exceção de Portugal e Espanha, a menção a países de perfil socioeconômico mais próximo ao nosso, como por exemplo praticamente inexistem. Países dos BRICS (Rússia, Índia, China e África do Sul), também estão ausentes destas parcerias, o que pode representar uma oportunidade a ser melhor explorada.

\section{Importância e disponibilidade dos incentivos}

\section{A percepção sobre importância dos incentivos para internacionalização}

Para avaliar a percepção individual da importância dos mecanismos de incentivo e de atividades para a consolidação de parcerias internacionais, vistas como atividades de estímulo institucional aos pesquisadores, foram utilizadas escalas com 5 níveis de avaliação (identificados de 1 a 5) que requisitavam o nível de importância percebida pelos pesquisadores, variando de $\mathbf{1}$ - Não importante até 5 - Muito importante. Os gráficos de barras empilhadas da Figura 1 e Figura 2 são apoiados pela literatura metodológica (Heiberger \& Robbins, 2014) e foram elaborados com a amostra dos respondentes da pesquisa. A indicação daqueles que acham que o incentivo considerado é neutro estão nas barras do lado esquerdo do gráfico.

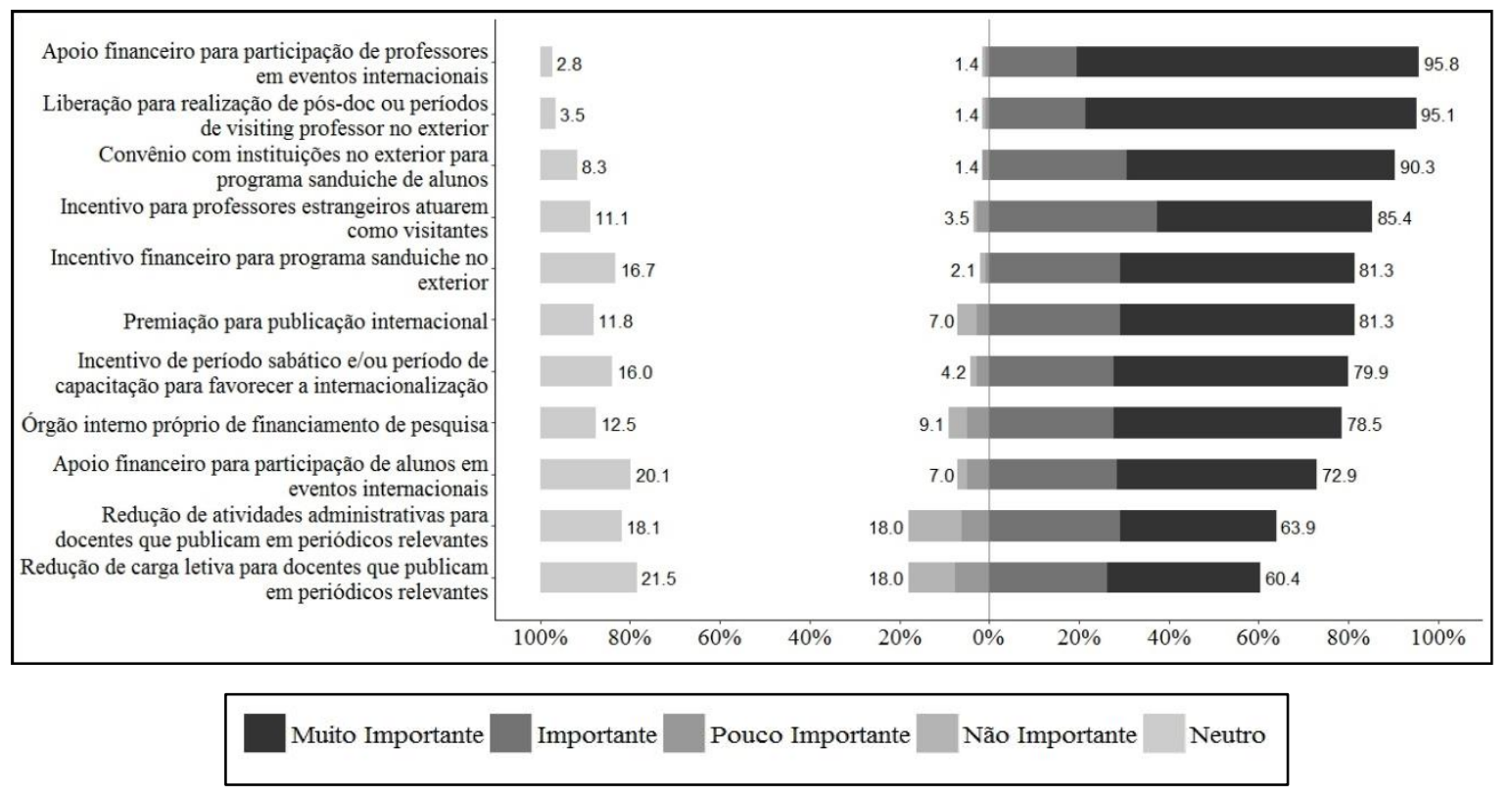

Figura 1. Importância Percebida dos Mecanismos de Incentivo Institucional

Percentuais acumulados conforme os níveis de importância percebida pelos respondentes para cada mecanismo de incentivo institucional à internacionalização. Fonte: Elaborado pelos autores com os dados da pesquisa 
$\mathrm{Na}$ Figura 1, em que se analisa os principais mecanismos de incentivo institucional à internacionalização, todos os mecanismos de incentivo foram considerados com alto grau de importância, e nenhum deles ficou abaixo 60\% de importante ou muito importante. De qualquer forma, a partir das respostas obtidas é possível observar uma certa hierarquia de importância, considerando os incentivos aos professores, aos alunos e outros tipos de incentivo.

Com relação aos incentivos direcionados aos professores, aqueles que ficaram em patamar mais alto de importância foram os que apoiam participação de professores em eventos internacionais e os que preveem liberação para atividades como visiting professor no exterior, com índices acima de $95 \%$ de importância. Incentivo a período sabático ficou próximo de $80 \%$ de importância, enquanto redução de atividades administrativas ou de carga letiva para docentes foram os que foram considerados com grau mais baixo, ambos com índice de importância pouco acima de 60\%. Neste caso, uma possível explicação é o fato dos respondentes considerarem a formação acadêmica de alunos em nível de graduação e pósgraduação como sua atividade fim na universidade, informação que foi capturada de comentários livres em algumas das respostas.

Com relação aos incentivos para alunos, convênio com instituições do exterior para bolsa sanduíche aparece com mais de $90 \%$ de importância, acima mesmo de incentivo financeiro (acima de $80 \%$ ) para que as mesmas bolsas sanduíche possam ser realizadas. Apoio financeiro para que alunos possam participar de eventos no exterior aparece mais abaixo, com pouco mais de $70 \%$ de importância. De forma geral, a internacionalização via apoio aos alunos parece ser considerada menos importante em comparação com o apoio aos próprios professores.

Outros mecanismos de incentivo foram considerados pelos pesquisadores como sendo relevantes para o processo de internacionalização. Dentre estes, apareceu como mais importante os incentivos para trazer professores visitantes ao país, com grau de $85 \%$ de importância. Premiação para publicação internacional vem a seguir com $81 \%$ e a existência de uma estrutura interna de financiamento à pesquisa na própria instituição em que o pesquisador atua aparece com mais de $78 \%$ de importância. Embora os índices sejam próximos, é importante destacar que premiação para publicação internacional fica numa posição intermediária de importância em comparação com outros tipos de incentivos, seja pela dificuldade maior das instituições públicas (maioria nesta amostra) em conceder prêmios por publicação, seja pelo fato dos respondentes pesquisados considerarem que publicação internacional é uma obrigação que não necessariamente deva ser premiada. Este é certamente um tema que merece ser aprofundado em pesquisas futuras.

A principal percepção capturada dos respondentes é que todos os mecanismos são importantes para a internacionalização, em especial os que estão relacionados com o apoio financeiro. Entretanto, tais mecanismos devem considerar o fortalecimento da comunidade cientifica, ou seja, a internacionalização da pesquisa será consequência de uma comunidade cientifica brasileira mais forte e plural e não apenas de incentivos isolados. Outra percepção é a necessidade da criação de incentivos institucionais para que os pesquisadores passem períodos no exterior para fortalecer vínculos de pesquisa, mais do que a pontuação por publicação.

A Figura 2 apresenta os resultados da percepção de importância das diversas atividades relacionadas a um aspecto específico da internacionalização: a consolidação de parcerias internacionais. Com este grupo de questões, procuramos avaliar como os pesquisadores consideram a importância de diversas atividades que de uma forma ou de outra propiciam de colaboração internacional. 


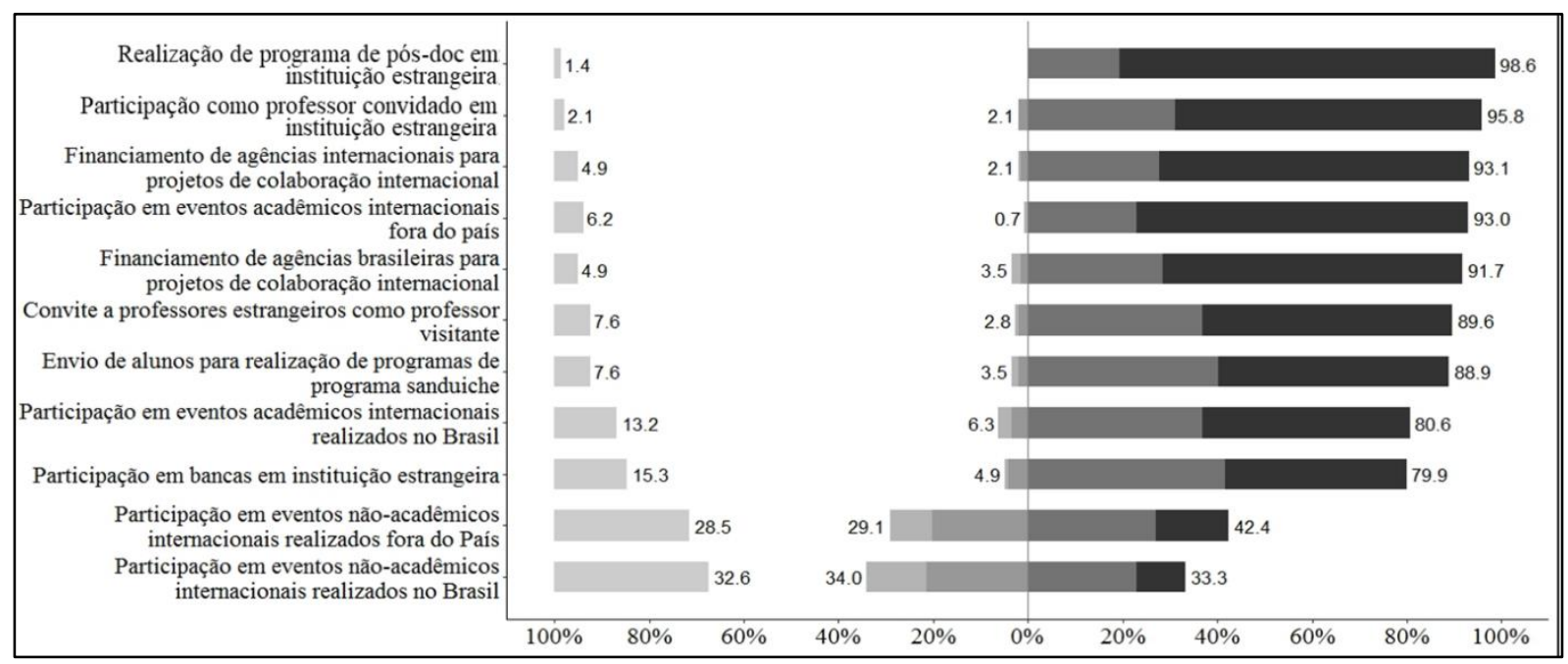

Muito Importante Importante Pouco Importante Não Importante Neutro

Figura 2. Atividades Mais Relevantes Para Obtenção de Parcerias Internacionais

Percentuais acumulados conforme os níveis de importância percebida pelos respondentes para consolidação de parcerias institucionais para a internacionalização. Fonte: Elaborado pelos autores com os dados da pesquisa.

Quase a totalidade dos pesquisadores indicou a atividade de atuar em uma universidade estrangeira, num pós-doc ou como professor visitante, como sendo o mais importante para consolidar parcerias internacionais para internacionalização. Participação em eventos acadêmicos fora do país foi classificada com importância de 93\%, enquanto participar de eventos internacionais no país teve importância bem menor, de $80 \%$, número próximo ao de participação em bancas de instituições estrangeiras. Já a participação de eventos não acadêmicos, no exterior ou no país, foi considerada de importância baixa para consolidar parcerias internacionais.

Financiamento de agências internacionais e brasileiras foi considerada com importância superior a 90\%, número próximo ao obtido para o convite a professores estrangeiros atuarem no país. Um pouco abaixo deste índice, mas também considerado de grande grau de importância para consolidação de parcerias internacionais, foi o envio de alunos em programas de bolsa sanduíche.

Observa-se na análise deste item do questionário que a maioria dos respondentes, consideram 9 das 11 opções apontadas com índice acima de $80 \%$, consideram as indicações importantes ou muito importantes somadas. Isso demonstra uma certa uniformidade no entendimento de que investir no conjunto destas atividades é necessário para consolidar parcerias que colocariam nossa academia num perfil de internacionalização mais elevado.

\section{Incentivos disponíveis aos pesquisadores em suas instituições}

Se no item anterior foi captada a percepção dos pesquisadores sobre a importância de diversos incentivos e atividades no processo de internacionalização de nossa academia, neste item identificamos os incentivos que estes mesmos pesquisadores têm à disposição em suas respectivas instituições.

De acordo com os dados indicados na Tabela 7, a liberação de professores para realização de pósdoc ou atuarem como professor visitante em instituição estrangeira é incentivo disponível para $74 \%$ dos respondentes. Logo abaixo, mas ainda presente em torno dois terços das instituições dos respondentes estão o apoio financeiro para professores participarem de eventos internacionais (65\%), incentivos para trazer professores estrangeiros $(63 \%)$ e convênios com instituições no exterior para realização de programa sanduíche $(63 \%)$. 
Outros incentivos disponíveis aos pesquisadores respondentes estão em patamar mais baixo. Um terço dos respondentes declarou a existência de um órgão interno de apoio a pesquisa em suas instituições, enquanto ajuda financeira para participação dos alunos em eventos internacionais aparece com $31 \%$. Premiação por publicação internacional são realizados em instituições de $32 \%$ dos respondentes e a existência de período sabático é disponível a um quarto dos respondentes.

Num patamar ainda mais baixo, apenas $17 \%$ dos respondentes indicou ter acesso a incentivo financeiro para seus alunos participarem de programa sanduíche no exterior. Redução de carga letiva e de atividades administrativas para pesquisadores que publicam em periódicos mais relevantes são incentivos disponíveis respectivamente a $14 \%$ e $6 \%$ dos respondentes. Outros incentivos, como apoio à tradução e cursos em Inglês, também foram apontados pelos respondentes com frequência mais baixa.

Tabela 7

\section{Mecanismos de Incentivo Existentes nas Instituições dos Respondentes}

\begin{tabular}{lcc}
\hline Incentivos & $\begin{array}{c}\text { Qtde } \\
(\mathbf{n = 1 7 2})\end{array}$ & $\mathbf{\%}$ \\
\hline Liberação para realização de pós-doc ou períodos de visiting professor no exterior & 126 & $74 \%$ \\
\hline Apoio financeiro para participação de professores em eventos internacionais & 111 & $65 \%$ \\
\hline Oportunidades para professores estrangeiros atuarem como visitantes & 108 & $63 \%$ \\
\hline Convênio com instituições no exterior para programa sanduíche de alunos & 108 & $63 \%$ \\
\hline Premiação pela publicação internacional & 55 & $32 \%$ \\
\hline Órgão interno próprio de financiamento de pesquisa & 54 & $31 \%$ \\
\hline Apoio financeiro para participação de alunos em eventos internacionais & 52 & $30 \%$ \\
\hline Incentivo a sabático para favorecer a internacionalização & 43 & $25 \%$ \\
\hline Incentivo financeiro para programa sanduíche no exterior & 29 & $17 \%$ \\
\hline Redução de carga letiva para quem publica em periódicos relevantes & 23 & $14 \%$ \\
\hline Redução de atividades administrativas para quem publica em periódicos relevantes & 11 & $6 \%$ \\
\hline Outros incentivos & 6 & $3 \%$ \\
\hline Não há incentivos & 1 & $1 \%$ \\
\hline
\end{tabular}

Nota. Mecanismos de incentivo existentes nas instituições dos pesquisadores, o percentual é a indicação no número de pesquisadores que marcaram o respectivo incentivo. Os respondentes poderiam assinalar mais de um incentivo. Fonte: Elaborado pelos autores.

Pouco mais de um quarto dos pesquisadores que participaram deste estudo relataram ter acesso a incentivos como premiação por publicação e apoio à participação de alunos em eventos internacionais. Se esses incentivos foram tidos por eles mesmos com grau de importância acima de $70 \%$ para a internacionalização, então há uma clara discrepância entre as condições oferecidas a esses pesquisadores e a sua necessidade de apoio para obter um maior grau de internacionalização.

\section{Análises estatísticas dos dados dos questionários}

\section{Teste das hipóteses $\mathrm{H} 1$ e $\mathrm{H} 2$}

A partir dos dados obtidos sobre a importância dos incentivos, da sua disponibilidade e do nível de internacionalização dos pesquisadores respondentes, foram elaboradas as duas hipóteses, H1 e H2, que foram testadas utilizando-se de regressões logísticas. 
Para testar a hipótese H1, que afirma que os pesquisadores não têm disponíveis os incentivos que eles consideram importantes para a sua internacionalização, foi realizada uma regressão logística considerando duas variáveis:

Vdisp $=$ incentivos que os pesquisadores possuem nas respectivas instituições e

Vimp = o nível de importância atribuído aos mecanismos de incentivo.

Desta forma a equação a ser estimada pode ser descrita como: Vdisp $=\alpha$ Vimp.

A regressão estimada para todos os mecanismos e todos os pesquisadores obteve o valor do parâmetro $\alpha$ de -0,1827. A relação inversa entre importância do mecanismo e probabilidade de haver o mecanismo para o pesquisador comprova a hipótese H1, pois mostra que a probabilidade de ocorrência de Vdisp diminui, em média, em -0,1827 para cada unidade de variação em Vimp. Ou seja, quanto maior a importância atribuída aos mecanismos de incentivo, menor a possibilidade desses mecanismos estarem disponíveis para os pesquisadores.

Para testar a hipótese $\mathrm{H} 2$, que afirma que os pesquisadores que têm acesso aos mecanismos de incentivo mais importantes publicam ou buscam publicar em periódicos mais relevantes, foram utilizadas 3 variáveis:

Vimp = nível de importância dos mecanismos de incentivo

Vpub $=$ periódicos internacionais relevantes em que publicou entre 2010 e 2016

Vsub = periódicos internacionais relevantes em que submeteu artigo entre 2010 e 2016

A variável Vimp foi criada somando todas as variáveis de mecanismos de incentivo e padronizando-as. As variáveis Vpub e Vsub foram criadas como variáveis binárias que assumem valor 1 caso o pesquisador tenha realizado a proposição.

Para comprovar a hipótese H2, foram feitas 2 regressões logísticas, em que Vimp é explicada pelas variáveis Vpub e Vsub, tendo como resultado o efeito da importância subjetiva dos pesquisadores sobre a probabilidade de ocorrerem as variáveis de publicação em periódicos, resultando em duas equações: Vimp $=\beta$ pub e Vimp $=\gamma$ Vsub. O resultado obtido da regressão foi: $\beta=0.345$ e $\gamma=0.162$. Ou seja, observamos uma relação positiva entre as variáveis Vimp, considerando Vpub e Vsub, o que indica que pesquisadores que buscam publicar ou publicam em periódicos mais relevantes têm acesso aos incentivos que eles consideram mais importantes, comprovando assim a hipótese H2.

\section{Análise explicativa da internacionalização utilizando regressão}

Para explicar o nível de internacionalização da pesquisa, foram escolhidas duas variáveis que combinam as dimensões relacionadas a disseminação e colaboração e são geralmente aceitas como a resultante mais importante do processo de internacionalização: (a) Publicação em co-autoria com pesquisadores de instituições estrangeiras em congresso internacional entre 2010 e 2016 e (b) Publicação em co-autoria com pesquisadores de instituições estrangeiras em periódicos entre 2010 e 2016.

Após a regressão, as variáveis que surgiram com maior impacto para explicar a internacionalização via coautoria internacional em congressos são, pela ordem, ter feito doutorado completo no exterior (coeficiente $=0.501$ ) e ter participado nos próprios eventos acadêmicos internacionais (coeficiente $=0.269$ ). Isso significa que a probabilidade de se ter coautoria em congressos aumenta em $50,1 \%$ se o pesquisador tem doutorado completo no exterior e aumenta $26,9 \%$ se tiver participação em eventos acadêmicos internacionais fora do Brasil. Além dessas variáveis, outras de menor significância encontradas foram: trazer professor visitante para a instituição (0.141), participar como professor convidado em instituições estrangeiras (0.113), ter alunos em programas sanduíche (0.097) e participar em bancas internacionais (0.073). 
No segundo caso, para se obter internacionalização via coautoria internacional em periódicos, as duas variáveis de maior impacto são o fato do pesquisador ter feito doutorado no exterior (coeficiente = 0.632 ) e ter alunos em programas sanduíche (coeficiente $=0.279$ ). Isso significa que a probabilidade de se ter coautoria em periódicos aumenta em $63,2 \%$ se o pesquisador tem doutorado completo no exterior e aumenta $27,9 \%$ se o professor tem alunos em programas sanduíche. Outras variáveis que também apresentaram significância, embora com coeficiente menores, para publicar em coautoria internacional em periódicos foram: participar como professor convidado em instituições estrangeiras (0.074), participar de chamadas de financiamento feitas por agências brasileiras (0.048), participar em eventos acadêmicos internacionais fora do Brasil (0.008) e participar em bancas internacionais (0.001).

Outras variáveis consideradas no modelo e que não apresentaram significância para a internacionalização, seja via publicação em coautoria em congressos ou periódicos foram: participação em eventos internacionais realizados no Brasil e participação em eventos não acadêmicos realizados no Brasil ou no exterior. Curiosamente, participação em chamadas de financiamento de agências internacionais para projetos de colaboração apresentaram efeito negativo em ambas as modalidades de internacionalização consideradas. A Tabela 8 apresenta o resultado completo das duas regressões realizadas com software R.

Tabela 8

Tabela de Resultados da Regressão - Nível de Internacionalização

\begin{tabular}{|c|c|c|}
\hline \multirow[b]{2}{*}{$\begin{array}{l}\text { Variáveis independentes } \\
\text { (explicativas) }\end{array}$} & \multicolumn{2}{|c|}{$\begin{array}{c}\text { Variável dependente } \\
\text { (de resposta) }\end{array}$} \\
\hline & Coautoria em periódicos & Coautoria em congressos \\
\hline Eventos acadêmicos internacionais & $\begin{array}{c}0.008 \\
(0.160)\end{array}$ & $\begin{array}{l}0.269 * \\
(0.160)\end{array}$ \\
\hline Alunos em programa sanduiche & $\begin{array}{l}0.279 * \\
(0.156) \\
\end{array}$ & $\begin{array}{c}0.097 \\
(0.150) \\
\end{array}$ \\
\hline Professores estrangeiros visitantes & $\begin{array}{l}-0.140 \\
(0.161) \\
\end{array}$ & $\begin{array}{c}0.141 \\
(0.158) \\
\end{array}$ \\
\hline Financiamento nacional & $\begin{array}{c}0.048 \\
(0.169)\end{array}$ & $\begin{array}{l}-0.086 \\
(0.171)\end{array}$ \\
\hline Financiamento internacional & $\begin{array}{l}-0.061 \\
(0.188) \\
\end{array}$ & $\begin{array}{l}-0.089 \\
(0.188) \\
\end{array}$ \\
\hline Participação em bancas no exterior & $\begin{array}{c}0.001 \\
(0.153) \\
\end{array}$ & $\begin{array}{c}0.073 \\
(0.153) \\
\end{array}$ \\
\hline Professor convidado em instituições estrangeiras & $\begin{array}{c}0.074 \\
(0.204) \\
\end{array}$ & $\begin{array}{c}0.113 \\
(0.201) \\
\end{array}$ \\
\hline Doutorado no exterior & $\begin{array}{c}0.632 * * * \\
(0.210)\end{array}$ & $\begin{array}{l}0.501 * * \\
(0.212) \\
\end{array}$ \\
\hline Constante & $\begin{array}{l}-1.321 \\
(0.981) \\
\end{array}$ & $\begin{array}{l}-2.434 * * \\
(0.984) \\
\end{array}$ \\
\hline Observations & 174 & 174 \\
\hline Log Likelihood & -112.292 & -113.063 \\
\hline Akaike information criterion & 242.584 & 244.126 \\
\hline
\end{tabular}

Nota. Os coeficientes, p-valores, indicados nas colunas das variáveis dependentes, representam o impacto de cada variável independentes sobre as variáveis dependentes, exemplificando: a participação em eventos acadêmicos internacionais representa baixo impacto na realização de coautoria em periódicos, ou seja, representa apenas um aumento de $0,8 \%$ na probabilidade de realizar a coautoria em periódicos. Por outro lado, a participação em eventos acadêmicos internacionais tem um bom impacto na realização de coautoria em congressos, ou seja, a participação aumenta a probabilidade em $26,9 \%$ de realizar a coautoria em congresso. Fonte: Elaborado pelos autores, resultados gerados no software R.

*p-valor $<0.1 ; * *$ p-valor $<0.05 ; * *$ p-valor $<0.01$. 


\section{Considerações Finais}

Este estudo investigou a inserção internacional de pesquisadores brasileiros, tomando como estudo de caso aqueles que fazem parte da comunidade de ADI, que fazem parte da área Administração, Contabilidade e Turismo na CAPES. Apesar de analisar dados dos pesquisadores concentrados em uma única sub-área, acredita-se que o fato da pesquisa incluir 172 pesquisadores de 17 unidades da federação e uma grande diversidade de instituições de ensino e pesquisa, contemplando as mais importantes do país, permite extrapolar as conclusões deste estudo para toda a área de Administração no país.

O foco deste estudo foi a influência dos ambientes institucionais sobre a atuação internacional dos pesquisadores, assim é possível imaginar que os pesquisadores da amostra estudada tenham tratamento muito semelhante aos seus colegas de outras sub-áreas, pois convivem dentro das mesmas instituições. Assim, a definição do foco do estudo numa sub-área específica tem apenas caráter de facilitar a operacionalização da pesquisa, garantindo uma certa uniformidade que facilita a interpretação dos resultados. Seria muito mais complicado, por exemplo, fazer uma análise precisa com uma dispersão muito maior de periódicos e congressos, o que fatalmente aconteceria se o estudo tivesse ampliado o escopo para toda a área de Administração.

A pesquisa partiu do modelo inicial de três dimensões de internacionalização - formação, disseminação e colaboração - proposto por Heinzl et al. (2015) e aprofundado por Diniz et al. (2017), e relacionou-as com o contexto institucional no qual o pesquisador está inserido. Desta forma, procurouse identificar as potenciais influências das estratégias de incentivos das instituições de ensino e pesquisa no comportamento individual e no perfil de internacionalização dos seus pesquisadores.

Assim, a contribuição teórica deste artigo é a articulação das influências institucionais nos comportamentos individuais dos pesquisadores, explicitando a existência de uma quarta dimensão, a institucional, que se soma às três anteriores descritas na literatura, que capturam o comportamento individual dos pesquisadores. Esta dimensão institucional foi aqui definida a partir dos mecanismos de incentivo para a internacionalização existentes em cada instituição, construídos com o objetivo de influenciar o processo de internacionalização de seus pesquisadores.

Para interpretar este relacionamento da dimensão institucional no comportamento em direção à internacionalização dos pesquisadores, capturou-se a sua percepção da importância sobre diversos mecanismos de incentivo e atividades de internacionalização, de uma forma genérica. Também foram identificados os incentivos de fato existentes nas respectivas instituições e o perfil de internacionalização desses pesquisadores com base na análise de sua atuação nas três dimensões propostas nos estudos anteriores.

Embora os pesquisadores demonstrem atuação individual crescentemente orientada para obter um maior grau de visibilidade internacional de sua pesquisa nas três dimensões de internacionalização, a menor ênfase na participação de redes internacionais, comportamento associado à dimensão colaboração pode sinalizar um viés existente nos mecanismos de incentivo existentes.

A comprovação das hipóteses $\mathrm{H} 1$ e H2, que afirmam que os pesquisadores em geral não têm acesso aos mecanismos de incentivo que consideram mais importantes para a internacionalização, ao mesmo tempo que aqueles com acesso a esses mesmos incentivos têm melhor resultado de internacionalização servem de alerta para os gestores acadêmicos que desenham as políticas de incentivo. Ouvir os principais interessados, ou seja, os próprios pesquisadores, oferece base empírica consistente para a construção de sistemas de incentivo.

Da observação destes resultados, emerge a contribuição para a prática deste artigo. Em primeiro lugar, as instituições precisam ficar mais atentas para a percepção dos pesquisadores ao desenvolver seus mecanismos de incentivo. Como a internacionalização é materializada pela atuação individual dos pesquisadores nas três dimensões, os incentivos também precisam cobrir adequadamente as mesmas dimensões. Este estudo mostrou que a dimensão colaboração tem menor ênfase nos mecanismos de 
incentivo, geralmente concentrado na dimensão disseminação, e isso se reflete no perfil de internacionalização dos pesquisadores.

Embora possamos admitir que as três dimensões se inter-relacionam, devemos reconhecer a relevância específica da dimensão colaboração na construção de um processo de internacionalização robusto e fundamental para a construção de um sistema internacional de inovação que contribua para a melhoria dos processos globais de geração e transferência de tecnologia (Ribeiro, Rapini, Silva, \& Albuquerque, 2018). É possível, por exemplo, que um pesquisador tenha tido excelente experiência no exterior, durante seu doutorado ou após, e ainda assim voltar sem ter conseguido se inserir consistentemente em redes internacionais. Na nossa amostra, $14 \%$ dos pesquisadores que tiveram experiência internacional não publicam internacionalmente desde 2010. Da mesma forma, a publicação feita sem colaboração internacional gera menos impacto que aquela com coautoria de pesquisadores de diferentes países (Meneghini, Packer, \& Nassi-Calo, 2008).

Por outro lado, aqueles pesquisadores que além de ter realizado sua formação no exterior, completa ou parcialmente, mas que continuam enviando alunos para programas sanduíche e continuam participando de eventos internacionais tem obtido mais sucesso na publicação com coautoria internacional em congressos ou periódicos. Este resultado demonstra que a manutenção de redes de colaboração internacional é um processo que exige constância e envolve também a articulação com alunos, o que exige apoio institucional para bancar os seus custos.

Outro resultado da pesquisa é a relativamente baixa inserção de nossos pesquisadores em comitês de periódicos, congressos e associações científicas. Um desenho de incentivos mais alinhado com a percepção dos pesquisadores deveria sinalizar que só teremos maior relevância na comunidade científica internacional se tivermos participação mais efetiva nesses comitês. Sem incentivos que apontem claramente nesta direção, nossos pesquisadores são induzidos a se satisfazerem com uma participação marginal, apenas como avaliadores ad hoc, por exemplo, nos espaços mais importantes de divulgação de suas pesquisas, ou a se contentarem em atuar em nichos menos relevantes. Como convivemos com recursos limitados, é mandatório uma dosagem mais equilibrada de incentivos para obtenção de resultados mais efetivos.

Os resultados obtidos neste estudo também mostram energia e otimismo de nossos pesquisadores na busca de uma maior presença internacional, a despeito das ineficiências do sistema de incentivos. Além de estarem cada vez mais ativos internacionalmente, ainda que longe de uma participação realmente relevante na comunidade internacional, os pesquisadores demonstram ambição de estarem presente nos canais mais importantes. Com mecanismos de incentivo mais ajustados, esta disposição à internacionalização presente em nossa comunidade tem potencial latente para produzir melhores resultados.

Este estudo, focado exclusivamente na visão dos pesquisadores, não aborda a visão dos gestores das instituições de ensino e pesquisa nem as políticas de incentivos por elas praticadas. Para uma visão mais abrangente da influência dos incentivos institucionais, é necessário incluir esses elementos na análise para entender as estratégias de internacionalização da academia brasileira. Estudos sobre as instituições de fomento e de avaliação dos programas de pós-graduação no país, assim como informações mais detalhadas sobre o perfil de publicações com coautoria internacionais são necessárias para complementar os resultados apresentados neste artigo.

Para a consolidação de uma quarta dimensão, a institucional, que se some àquela identificada na revisão de literatura apresentada neste artigo, será necessário ainda: coleta de dados que inclua documentos públicos sobre políticas de internacionalização em instituições públicas e privadas, bem como de entrevistas com gestores de PPGs, líderes de linha e pesquisadores sêniores e/ou com maior perfil de internacionalização. Alterações de percepção também devem ser capturadas, de acordo com o tempo de carreira e da instituição de atuação, pública ou privada. E ainda novos estudos compreendendo outras sub-áreas da Administração poderão contribuir para aprofundar o conhecimento necessário sobre o processo de internacionalização e os incentivos praticados pelas instituições com o objetivo de influenciar o comportamento de seus pesquisadores. Futuros estudos devem também incluir maior 
detalhamento sobre o perfil dos pesquisadores, como por exemplo, a identificação da relação da internacionalização com o acesso a bolsa produtividade do CNPq, dado que não foi coletado neste estudo com foco apenas nos incentivos das instituições nas quais os pesquisadores estão inseridos.

\section{Referências}

Association for Information Systems. (n.d.). The AIS faculty directory. Retrieved from https://aisnet.org/?FacultyDirectory

Bentley, P. J., \& Kyvik, S. (2012). Academic work from a comparative perspective: A survey of faculty working time across 13 countries. Higher Education, 63(4), 529-547. http://doi.org/10.1007/s10734-011-9457-4

Bentley, P. J., \& Kyvik, S. (2013). Individual differences in faculty research time allocations across 13 countries. Research in Higher Education, 54(3), 329-348. http://doi.org/10.1007/s11162-0129273-4

Bertero, C. O., Silveira, R. A. D., Cabral, S., Faria, A., \& Rossoni, L. (2013). Os desafios da produção de conhecimento em administração no Brasil. Cadernos EBAPE.BR, 11(1), 181-196. http://doi.org/10.1590/S1679-39512013000100012

Coordenação de Aperfeiçoamento de Pessoal de Nível Superior. (2016). Documento de área administração pública e de empresas, ciências contábeis e turismo. Brasilia, DF. Recuperado de http://www.capes.gov.br/images/documentos/Documentos_de_area_2017/27_ADMI_docarea_2 016.pdf

Diniz, E. H., Favaretto, J. E. R., Oliveira, H. P. G. D., \& Brólio, D. R. (2017). Formação, disseminação e colaboração: internacionalização em administração de sistemas de informação. Revista de Administração Contemporânea, 21(6), 811-831. Recuperado de http://www.scielo.br/pdf/rac/v21n6/1982-7849-rac-21-06-0811.pdf. http://doi.org/10.1590/1982-7849rac2017160319

Heiberger, R. M., \& Robbins, N. B. (2014). Design of diverging stacked bar charts for likert scales and other applications. Journal of Statistical Software, 57(5), 1-32. http://doi.org/10.18637/jss.v057.i05

Heinzl, A., Winter, R., \& Bichler, M. (2015). Internationalization of information systems research and teaching. Business \& Information Systems Engineering, 57(4), 225-228. http://doi.org/10.1007/s12599-015-0388-y

Hewson, C. M., Laurent, D., \& Vogel, C. M. (1996). Proper methodologies for psychological and sociological studies conducted via the internet. Behavior Research Methods, Instruments, \& Computers, 28(2), 186-191. https://doi.org/10.3758/BF03204763

Knight, J. (2007). Internationalization: Concepts, complexities and challenges. In J. J. F. Forest \& P. G. Altbach (Eds.), International handbook of higher education (pp. 207-227). Dordrecht: Springer Netherlands. https://doi.org/10.1007/978-1-4020-4012-2_11

Kwiek, M. (2016). The European research elite: A cross-national study of highly productive academics in 11 countries. Higher Education, 71(3), 379-397. https://doi.org/10.1007/s10734-015-9910-x

Meneghini, R., Packer, A. L., \& Nassi-Calo, L. (2008). Articles by Latin American authors in prestigious journals have fewer citations. PLoS One, 3(11), e3804. https://doi.org/10.1371/journal.pone.0003804 
Incentivos para Internacionalização são Adequados? Percepção dos Pesquisadores em Administração da Informação

Ribeiro, L. C., Rapini, M. S., Silva, L. A., \& Albuquerque, E. M. (2018). Growth patterns of the network of international collaboration in science. Scientometrics, 114(1), 159-179. https://doi.org/10.1007/s11192-017-2573-x

Rostan, M., Ceravolo, F. A., \& Metcalfe, A. S. (2014). The internationalization of research. In F. Huang, M. Finkelstein, \& M. Rostan (Orgs.), The internationalization of the academy (pp. 119-143). Dordrecht: Springer Netherlands. https://doi.org/10.1007/978-94-007-7278-6_7

Schmidt, W. C. (1997). World-wide web survey research: Benefits, potential problems, and solutions. Behavior Research Methods, Instruments, \& Computers, 29(2), 274-279. https://doi.org/10.3758/BF03204826

Shin, J. C., \& Cummings, W. K. (2010). Multilevel analysis of academic publishing across disciplines: Research preference, collaboration, and time on research. Scientometrics, 85(2), 581-594. https://doi.org/10.1007/s11192-010-0236-2

Walsham, G., Robey, D., \& Sahay, S. (2007). Foreword: Special issue on information systems in developing countries. MIS Quarterly, 31(2), 317-326. https://doi.org/10.2307/25148793

Wood, T., Jr., Tonelli, M. J., \& Cooke, B. (2011). Colonização e neocolonização da Gestão de Recursos Humanos no Brasil (1950-2010). Revista de Administração de Empresas, 51(3), 232-243. https://doi.org/10.1590/S0034-75902011000300004

\author{
Autores \\ Eduardo H. Diniz \\ Rua Itapeva, 474, 01313-902, São Paulo, SP, Brasil \\ E-mail: eduardiniz@gmail.com \\ Henrique Pontes Gonçalves de Oliveira \\ Rua Itapeva, 474, 01313-902, São Paulo, SP, Brasil \\ E-mail: henrique.pontes@uol.com.br \\ José Eduardo Ricciardi Favaretto \\ Rua Itapeva, 474, 01313-902, São Paulo, SP, Brasil \\ E-mail: jose@ favaretto.net \\ Débora Richter Brólio \\ Rua Itapeva, 474, 01313-902, São Paulo, SP, Brasil \\ E-mail: debora.richter@gmail.com
}

\title{
Contribuições
}

$1^{\circ}$ autor: coordenador geral da pesquisa, elaboração do questionário, redação do texto.

$2^{\circ}$ autor: redação do texto, elaboração do questionário, coleta de dados.

$3^{\text {o }}$ autor: elaboração do questionário, coleta de dados.

$4^{\circ}$ autor: coleta de dados.

\section{Financiamento}

Pesquisa financiada pelo FGVpesquisa.

\section{Conflito de Interesses}

Não há qualquer tipo de conflito de interesses.

\section{Verificação de Plágio}

A RAC mantém a prática de submeter todos os documentos aprovados para publicação à verificação de plágio, mediante o emprego de ferramentas específicas, e.g.: iThenticate. 


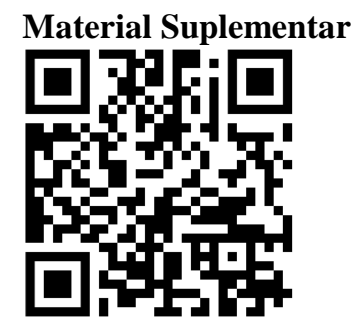

Todos os dados e materiais foram disponibilizados publicamente por meio da plataforma Mendeley e podem ser acessados em: Oliveira, Henrique; Diniz, Eduardo; Richter, Débora; Favaretto, José (2019), "Data for: "How to internationalize our research? Perception of brazilian researchers on institutional incentives", published by RACRevista de Administração Contemporânea", Mendeley Data, v1. Recuperado de http://dx.doi.org/10.17632/3b529zn236.1 